\title{
Heat Transfer Related to Gas Hydrate Formation/Dissociation
}

\author{
Bei Liu, Weixin Pang, Baozi Peng, Changyu Sun and Guangjin Chen \\ State Key Laboratory of Heavy Oil Processing, \\ China University of Petroleum, Beijing 102249, \\ P. R. China
}

\section{Introduction}

Gas hydrates are ice-like crystalline compounds comprised of small guest molecules, such as methane or other light hydrocarbons, which are trapped in cages of a hydrogen-bonded water framework. It has drawn attention in the gas and oil industry since 1930s because it was found that the formation of gas hydrates may block oil/gas pipelines (Sloan and Koh, 2007). However, with the gradual discovery of huge reserve of natural gas hydrates in the earth as well as the understanding of the peculiar properties of gas hydrates, more and more studies have focused on how to benefit from gas hydrates in recent decades. The most important aspect of gas hydrates research is attributed to the exploration and exploitation of natural gas hydrates. Additionally, people also try a lot in the development of novel technologies based on hydrates, such as separation of gas mixture via forming hydrates, storage of natural gas or hydrogen in the form of solid hydrates, and sequestration of $\mathrm{CO}_{2}$, etc. As the formation of gas hydrates is an exothermic process, heat transfer always accompanies hydrate formation or dissociation. The understanding of heat transfer mechanism is critical to the modeling of formation/dissociation kinetic process of gas hydrates, which favors the best exploitation of natural gas hydrates and the best design of reactor for hydrate production or decomposer for hydrate dissociation with respect to different kinds of hydrate application objects.

In recent years, a variety of experimental and theoretical works focused on heat transfer involved in formation/dissociation of gas hydrates have been reported. They are summarized in this chapter accompanying presentation of our new work relevant to this topic. This chapter is organized as follows. In section 2, we present progresses in experimental measurement of the thermal conductivities of different kinds of gas hydrates, including pure gas hydrates and hydrate-bearing sediments. The achievements on mechanism and modeling of heat transfer occurring in the growth of hydrate film at the guest/water interface, as well as its influence upon the hydrate film growth rate are summarized in section 3. Our new experimental study on heat transfer in stirring or flowing hydrate system is given in section 4 . Section 5 presents our recent work on the experimental and modeling studies on heat transfer in quiescent reactors for producing or decomposing big blocks of hydrates, and the formulation of the influence of heat transfer upon the hydrate formation/dissociation rate. In section 6, the mechanism of heat transfer in hydrate 
bearing-sediment are analyzed and discussed. Finally, some concluding remarks are given in section 7 .

\section{Thermal conductivity of gas hydrate}

Thermal conductivity is a kind of basic data for studying the heat transfer of hydrates involved systems. In recent decades, a number of researchers have made their efforts to measure the thermal conductivities of different types of gas hydrates at different conditions. Regarding to measurement technique, the most widely adopted ones are standard needle probe technique and transient plane source (TPS) technique (Gustafsson et al., 1979, 1986). For example, thermal conductivity of methane hydrate has been determined by deMartin (2001), Krivchikov et al. (2005), and Waite et al. (2007) using the needle probe technique. With same technique, thermal conductivities of several other gas hydrates, such as tetrohydrofuran (THF) hydrate (Cortes et al., 2009), xenon hydrate (Krivchikov et al., 2006), HCFC-141b hydrate (Huang et al., 2004), and CFC-11 hydrate (Huang et al., 2004) have been measured. Transient plane source (TPS) technique in double- and single-sided configurations has been used more recently to measure thermal conductivity of gas hydrates (Huang and Fan, 2004; Li et al., 2010; Rosenbaum et al., 2007). This technique is based on the transient method and the needle probe, but it has a very small probe (Gustafsson et al., 1979, 1986). It allows measurements without any disturbance from the interfaces between the sensor and the bulk samples. In addition, it is possible to measure thermal conductivity, thermal diffusivity, and heat capacity per unit volume simultaneously (Gustafsson et al., 1979). It is hard to draw a definite conclusion that which technique is better for pure gas hydrate samples synthesized in laboratory; however, for in-situ determination of the thermal properties of hydrate-containing sediments, the single-sided TPS technique may be more suitable as the needle probe and double-sided TPS techniques need the probe to be surrounded by the hydrates (English and Tse, 2010).

There are several factors, such as the porosity of the samples, temperature, pressure, and measurement time, that influence thermal conductivity of gas hydrates. As pointed out by English and Tse (2010), for relatively pure hydrates, reducing the porosity of the samples by compacting them is critical for obtaining the reliable thermal conductivity in the intermediate temperature range. For hydrate-bearing sediments, Tzirita (1992) concluded that porosity is also a critical factor in controlling the thermal conductivity. More recently, Cortes et al. (2009) carried out a systematic measurement of the thermal conductivity of THF-hydrate saturated sand and clay samples. They found the influence is a complex interplay among particle size, effective stress, porosity, and fluid-versus-hydrate filled pore spaces, not only porosity. With respect to temperature effect, many studies found that hydrates exhibit a glass-like temperature dependence of thermal conductivity (Andersson and Ross, 1983; Handa and Cook, 1987; Krivchikov et al., 2005, 2006; Ross et al., 1981; Ross and Andersson, 1982; Tse and White, 1988). Among these studies, the works of Krivchikov et al. $(2005,2006)$ are interesting as they found that both methane and xenon hydrates show crystal-like temperature dependence below $90 \mathrm{~K}$, while exhibiting glass-like behavior above $90 \mathrm{~K}$. The effect of pressure has also been investigated by many groups (Andersson and Ross, 1983; Rosenbaum et al., 2007; Waite et al., 2007). Only weak pressure dependency was observed by them. Finally, the relationship between thermal conductivity and measurement time for methane hydrate 
has been studied by $\mathrm{Li}$ et al. (2010) very recently. They found that in $24 \mathrm{~h}$, thermal conductivity increases $5.45 \%$ at $268.15 \mathrm{~K}$; however, at $263.15 \mathrm{~K}$, the increment is $196.29 \%$. From their results we may say that measurement time needs to be considered for thermal conductivity studies at relatively low temperatures.

To give readers a clear picture of measured thermal conductivities of different kinds of gas hydrates, the results of pure gas hydrates and hydrate-bearing sediments are listed in Table 1.

\begin{tabular}{|c|c|c|c|c|}
\hline compound & $\mathrm{T} / \mathrm{K}$ & $\mathbf{P} / \mathbf{M P a}$ & $\lambda / W$ m-1 K- & Ref \\
\hline \multicolumn{5}{|c|}{ pure gas hydrates } \\
\hline methane & $253-290$ & 31.5 & $\sim 0.62$ & Waite et al., 2007 \\
\hline $\begin{array}{c}\text { methane } \\
\text { (compacted samples) }\end{array}$ & $263.05-277.97$ & 6.6 & $\sim 0.57$ & Huang and Fan, 2004 \\
\hline $\begin{array}{c}\text { methane } \\
\text { (compacted samples) }\end{array}$ & $261.5-277.4$ & $3.8-14.2$ & $\sim 0.68$ & Rosenbaum et al., 2007 \\
\hline tetrahydrofuran & $15-100$ & & $0.04-0.12$ & Tse and White, 1988 \\
\hline tetrahydrofuran $\cdot 17 \mathrm{H}_{2} \mathrm{O}$ & 261 & & 0.5 & Waite et al., 2005 \\
\hline tetrahydrofuran $\cdot 17 \mathrm{H}_{2} \mathrm{O}$ & 261 & $0.05-1$ & 0.58 & Cortes et al., 2009 \\
\hline xenon & 245 & $\sim 0.05$ & 0.36 & Handa and Cook, 1987 \\
\hline ethylene oxide & 263 & & 0.49 & Cook and Laubitz, 1983 \\
\hline cyclobutanone & 260 & 100 & $\sim 0.47$ & $\begin{array}{c}\text { Andersson and Ross, } \\
1983\end{array}$ \\
\hline 1,3-dioxolane & 260 & 100 & $\sim 0.51$ & $\begin{array}{c}\text { Andersson and Ross, } \\
1983\end{array}$ \\
\hline propane & 275 & 1 & $\sim 0.4$ & Stoll and Bryan, 1979 \\
\hline sodium sulphide $9 \mathrm{H}_{2} \mathrm{O}$ & 295 & 0.001 & 0.12 & Lunden et al., 1986 \\
\hline HCFC-141b & $\sim 250$ & 0.1 & $\sim 0.5$ & Huang et al., 2004 \\
\hline CFC-11 & $\sim 250$ & 0.1 & $\sim 0.5$ & Huang et al., 2004 \\
\hline \multicolumn{5}{|c|}{ hydrate-bearing sediments } \\
\hline $\begin{array}{c}\text { natural methane } \\
\text { hydrate-layer sand }\end{array}$ & $263-283$ & 0.1 & $3.8-5.8$ & Yamamoto et al., 2008 \\
\hline $\begin{array}{l}\text { sand with } 100 \% \\
\text { THF } 17 \mathrm{H}_{2} \mathrm{O} \text { hydrate }\end{array}$ & 261 & $0.05-1$ & $4.1-4.5$ & Cortes et al., 2009 \\
\hline $\begin{array}{c}\text { clay with } 100 \% \\
\text { THF } \cdot 17 \mathrm{H}_{2} \mathrm{O} \text { hydrate }\end{array}$ & 261 & $0.05-1$ & $2.8-3.0$ & Cortes et al., 2009 \\
\hline
\end{tabular}

Table 1. Thermal conductivities, $\lambda$, of pure gas hydrates and hydrate-bearing sediments 


\section{Heat transfer in growth of hydrate film}

Generally, because most of hydrate formers (guests) are water insoluble, the initial formation of hydrate occurs at the guest/water interface, taking the form of thin porous crystalline film. The further growth of hydrate is controlled by mass transfer of water or hydrate former through the film. Many experimental and/or theoretical studies on the growth of hydrate film have been carried out by several groups (Freer et al., 2001; Ma et al., 2002; Mochizuki and Mori, 2006; Mori, 2001; Ohmura et al., 2000, 2005; Peng et al., 2007, 2008, 2009; Saito et al., 2010, 2011; Sun et al., 2007; Taylor et al., 2007; Uchida et al., 1999, 2002), including the morphology of hydrate film, the growth rate of hydrate film, the thickness of hydrate film, the mechanism of hydrate film growth, and so on. However, so far it is still a controversial topic on the growth mechanism of hydrate film. Recently, more attention has been paid to the mechanism of heat transfer on hydrate film growth at the guest/water interface than intrinsic kinetic and mass transfer mechanisms. In this part, different hydrate film growth models, especially heat transfer models that have been developed by various research groups are summarized.

Experimental and molecular dynamic simulation studies on the initial formation of hydrate at the guest/water interface suggest that the interface where there is a significant concentration gradient is the place to initiate and sustain hydrate formation (Moon, et al. 2003; Vysniauskas and Bishnoi, 1983). Englezos et al. (1987a, 1987b) studied the kinetics of formation of methane, ethane, and their mixture hydrates in a semi-batch stirred tank reactor. They presented an intrinsic kinetic model for the hydrate particle growth and the rate of growth per particle was given by:

$$
\left(\frac{d n}{d t}\right)_{P}=K^{*} A_{P}\left(f-f_{e q}\right)
$$

with

$$
\frac{1}{K^{*}}=\frac{1}{K_{r}}+\frac{1}{K_{d}}
$$

where $n$ is the moles of gas consumed, $t$ is the hydrate reaction time, $K^{*}$ is the combined rate parameter, $A_{P}$ is the surface area of particles, $f$ is the gas fugacity, $f_{e q}$ is the equilibrium fugacity, $K_{r}$ and $K_{d}$ are the reaction rate constant and mass transfer coefficient around the particle, respectively. Similarly, based on the assumption that the intrinsic kinetics is the control step of hydrate formation and growth, Ma et al. (2002) developed a model to correlate the lateral growth rate of hydrate film. The model was formulated as the following form:

$$
r_{f}=A \times\left[e^{B(-\Delta g /(R T))}-1\right]
$$

where $r_{f}$ is the lateral growth of hydrate film. Parameters $A$ and $B$ are system composition dependent and were determined by fitting experimental data. The Gibbs free energy difference $(\Delta g)$ was selected as the driving force to describe the hydrate growth process. The experimental results indicated that this model could correlate the lateral film growth rate perfectly (Ma et al., 2002; Sun et al., 2007). 
Except for the models described above, some researchers suggested that the growth rate of hydrate film is controlled by heat diffusion and some models were developed correspondingly. For example, Uchida et al. (1999) presented a model analysis of the twodimensional growth of a carbon dioxide hydrate film (Figure 1).

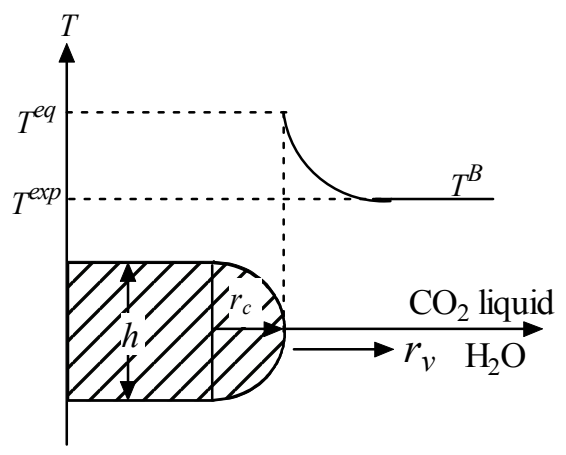

Fig. 1. Hydrate film model of Uchida et al (1999)

In this model, they assumed that one half of the film is in water phase, and the other half is in guest phase. The hydrate film has a semicircular front and is uniform in thickness. In addition, this model assumes that hydrate crystals successively form only at the front of the hydrate film and the front is maintained at the three-phase (water/guest-fluid/hydrate) equilibrium temperature. The heat released by the hydrate crystal formation is diffused away from the film front and into the water and guest-fluid phase. Based on these assumptions, they formulated the heat balance at the edge of the film as

$$
v_{f} \rho_{h} \Delta h_{h}=\lambda_{w} \Delta T / r_{c}
$$

where $v_{f}$ is the rate of linear growth of the film, $\rho_{h}$ is the mass density of the film, $\Delta h_{h}$ is the heat of hydrate formation (per unit mass of hydrate), $\lambda_{w}$ is the thermal conductivity of water, $\Delta T$ is the difference between the temperature at the film edge, $T^{e q}$, and the undisturbed temperature in the fluid phases, $T^{B}$, and $r_{c}$ is the radius of curvature of the edge. Uchida et al. (1999) correlated their experimental data on $v_{f}$ versus $\Delta T$ by means of a linear regression analysis as follows:

$$
v_{f}=(1.73 \pm 0.16) \Delta T
$$

In Uchida et al.'s model (Uchida et al., 1999), the conductive heat transfer from the film front was deduced from the temperature gradient, which was deemed as with little physical reasoning (Mochizuki and Mori, 2006; Mori, 2001). Mori (2001) presented an alternative model of hydrate film growth based on the idea that the front of hydrate film, which grew on the interface between stagnant water and guest fluid, could be viewed to be held in stratified flow of the two fluids with the velocity which was opposite in sign but equal in magnitude to the velocity of the hydrate film front. In his work, the heat removed from the film front to the liquid phases was treated as a steady convective heat transfer and other assumptions were same as those of Uchida et al. (1999). The heat balance over the hemicircular front of the film was formulated as follows: 


$$
v_{f} \delta \rho_{g} \Delta h_{h}=\frac{1}{4} \pi \delta\left(\bar{\alpha}_{w}+\bar{\alpha}_{g}\right) \Delta T
$$

Mori (2001) assumed that the heat transfer coefficients, $\bar{\alpha}_{w}$ and $\bar{\alpha}_{g}$, could be given by the simplest type of convective heat transfer correlation in a dimensionless form and deduced a $\delta-v_{f}$ relation correspondingly:

$$
v_{f} \delta=C \Delta T^{3 / 2}
$$

where

$$
C=\left[\frac{\pi A}{4} \frac{1}{\rho_{h} \Delta h_{h}}\left(\frac{\lambda_{w}}{v_{w}^{1 / 3}} \operatorname{Pr}_{w}^{1 / 3}+\frac{\lambda_{g}}{v_{g}^{1 / 3}} \operatorname{Pr}_{g}^{1 / 3}\right)\right]^{3 / 2}
$$

In Equation 8, $\lambda_{w}$ and $\lambda_{g}$ are the thermal conductivity of water and the hydrate former, respectively, $v_{w}$ and $v_{g}$ are the kinematic viscosity of water and the hydrate former, respectively, and $\operatorname{Pr}_{w}$ and $\operatorname{Pr}_{g}$ are the Prandtl number of water and the hydrate former, respectively.

Mochizuki and Mori (2006) modified Mori's model and presented another model, as shown in Figure 2. They assumed that there is a transient two-dimensional conductive heat transfer from the film front to the water and guest-fluid phases plus the hydrate film itself. In this model, the hydrate film was assumed to exist on the water side of the water-guest fluid interface and the interface infinitely extend. No convection occurs in either of the water and guest-fluid and other assumptions were same as those of Uchida et al. (1999). The rate of heat removal from the front to the surroundings is balanced by the rate of heat generation of hydrate-crystal formation.

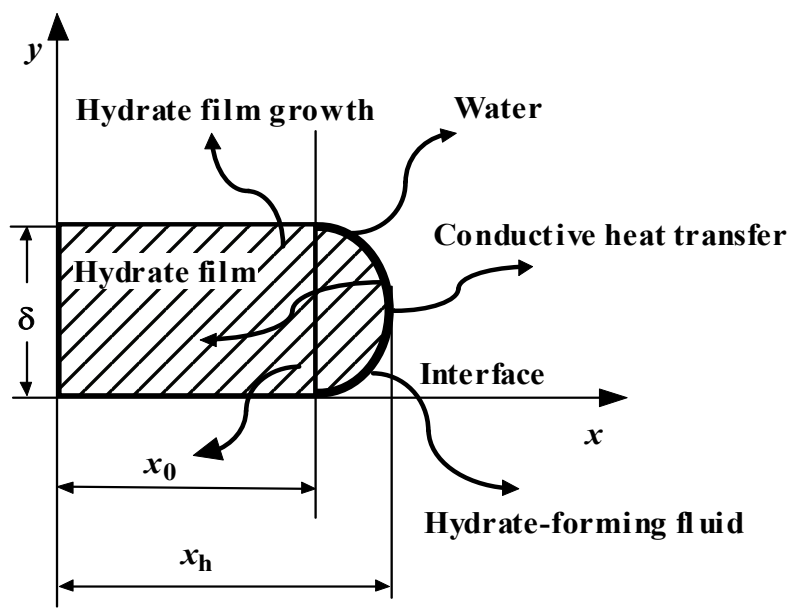

Fig. 2. Hydrate film model of Mochizuki and Mori (2006)

The linear growth rate of the hydrate film along the water/guest-fluid interface, $v_{f}=d x_{h} / d t$, was given in the following equation: 


$$
\rho_{h} \delta \Delta h_{H} v_{f}=\int_{-\pi / 2}^{\pi / 2}\left(\left.\lambda_{h} \frac{\partial T}{\partial r}\right|_{r=r_{h}-}-\left.\lambda_{w} \frac{\partial T}{\partial r}\right|_{r=r_{h}+}\right) r_{h} d \theta
$$

where $\partial T /\left.\partial r\right|_{r=r_{h}-}$ and $\partial T /\left.\partial r\right|_{r=r_{h}+}$ are the radial temperature gradients on the hydrate side and the fluid side, respectively, at $r=r_{h}$ (i.e., the $x$ position of the hydrate-film front). It should be pointed out that this model is computationally complicated and hence cumbersome to use. In addition, the assumptions adopted in this model, that is, the film front is in the water phase or one half in water phase and the other half in guest-fluid phase are too arbitrary. Therefore, Peng et al. (2007) proposed another hydrate film model based on Mori's model. In their model, they assumed part of thickness $x$ of hydrate film is in guest phase and another part of thickness $\delta-x$ is in water phase, as shown in Figure 3 . The value of $x$ is guest composition dependent.

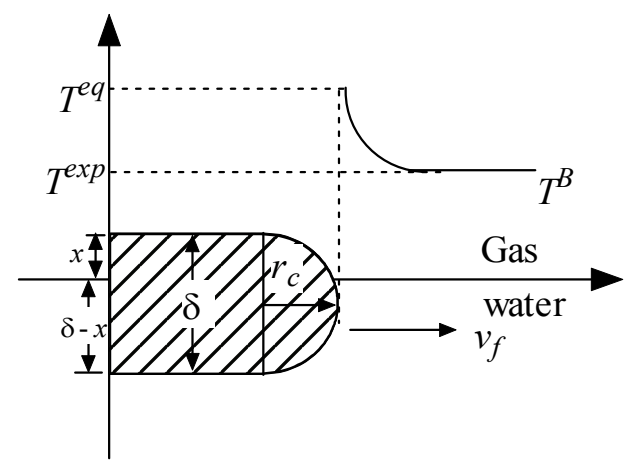

Fig. 3. Hydrate film model of Peng et al. (2007)

In Peng et al.'s model (Peng et al., 2007), the thickness of hydrate film was assumed to vary with driving force inversely, i.e.,

$$
\delta=k / \Delta T
$$

The lateral rate of hydrate film was then correlated by the following equation:

$$
v_{f}=\frac{C}{k} \Delta T^{\frac{5}{2}}
$$

where the constant $C$ in Mori's model was reformulated by a generalized expression, as shown below:

$$
C=\left[\frac{1}{6 \rho_{h} \Delta h_{h}}\left(\lambda_{w}{ }^{2 / 3} \rho_{w}{ }^{1 / 3} c_{p, w}{ }^{1 / 3}\left(\pi-\arccos \left(1-\frac{2 x}{\delta}\right)\right)+\lambda_{g}{ }^{2 / 3} \rho_{g}{ }^{1 / 3} c_{p, g}{ }^{1 / 3} \arccos \left(1-\frac{2 x}{\delta}\right)\right)\right]^{3 / 2}
$$

The modified convection heat transfer model presented by Peng et al.(2007), i.e., Equation 11, has been used to correlate the lateral growth rate of hydrate film of different crystal structures in wide temperature and pressure ranges (Peng et al., 2007, 2009). It can be concluded that validity of Equation 11 is independent of the composition of hydrate former and the structure type of hydrates (Peng et al., 2007). 
For investigating the growth mechanism of the hydrate film, Freer et al. (2001) also studied methane hydrate film growth on the water/methane interface experimentally and proposed a model of lateral hydrate film growth. They calculated the $v_{f}$ of methane hydrate film by assuming that one dimensional conductive heat transferred from the film front to water. As the calculated $v_{f}$ was much lower than the experimentally measured $v_{f}$, they suggested that the hydrate film growth was controlled by both intrinsic kinetics and heat transfer. Their model was expressed as:

$$
\begin{aligned}
\lambda_{h} \rho_{h} v_{f} & =K\left(T^{e q}-T^{B}\right) \\
\frac{1}{K} & =\frac{1}{k}+\frac{1}{h}
\end{aligned}
$$

where $\lambda_{h}$ is the thermal conductivity of hydrate, $K$ is the total resistance, $h$ is the heat transfer coefficient, and $k$ is the methane hydrate kinetic rate constant.

Additionally, for investigating which step is the main contribution to the hydrate film growth, Peng et al. (2008) also presented a model based on the assumption that hydrate lateral film growth is controlled by both intrinsic kinetics and heat transfer, as shown in Figure 4 .

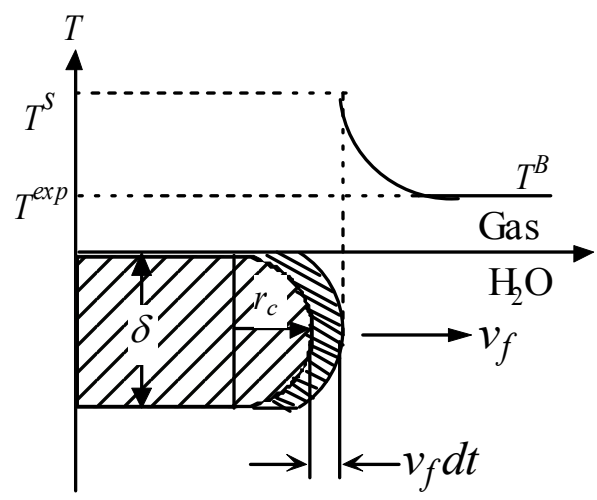

Fig. 4. Hydrate film model of Peng et al. (2008)

This model is similar to the model of Uchida et al. (1999). However, in this model Peng et al. kept the hydrate film at $T^{S}$ rather than at the three-phase (water/guest/hydrate) equilibrium temperature and they proposed the intrinsic rate of hydrate film growth should not be of a linear relation with the driving force. Therefore, the balance of the heat removed from the film front with that generated by the hydrate formation was formulated by the equation proposed by Freer et al. (2001),

$$
v_{f} \rho_{h} \Delta h_{h}=k_{1}\left(T^{S}-T^{B}\right)
$$

and the intrinsic kinetic equation was adopted as following:

$$
v_{f}=k_{2}\left(T^{e q}-T^{S}\right)^{n}
$$


From Equations 15 and 16, the following equation can be obtained:

$$
\frac{\rho_{h} \Delta h_{h}}{k_{1}} v_{f}+\left(\frac{v_{f}}{k_{2}}\right)^{1 / n}=T^{e q}-T^{B}=\Delta T
$$

Based on their experiment data, Peng et al. calculated the temperature differences between the hydrate film front and the bulk water at different driving forces, which were taken as an important factor on judging the dominating contribution for hydrate film growth at the gas/water interface. They found that the effect of heat transfer on hydrate film growth is much smaller than that of intrinsic kinetics, and suggested that the intrinsic kinetic is the main control step for hydrate film growth of methane and carbon dioxide hydrate.

It should be pointed out that for the models mentioned above, the parameters were obtained by correlating with different experimental data set. As the experimental data were obtained in different experiment apparatus and the stochastic induction time of hydrate nucleation may also affect the measurement of hydrate film growth rate for different experiment device, it is hard to draw a definite conclusion that which model is better. More efforts need to be made on hydrate film growth in the future.

\section{Heat transfer in stirring or flowing hydrate system}

Stirring is an important technique that can enhance heat and mass transfer, and thus accelerating the speed of hydrate formation/dissociation. The state of hydrates formed under stirring is usually in slurry, which is also the case when hydrates are formed in gasoil-water multi-phase flowing systems containing hydrate anti-agglomerants (AA). As a result, the determination of heat transfer coefficient of hydrate slurry is crucial for investigating the heat transfer in hydrate forming/dissociating processes under stirring or flowing. Unfortunately, there are very few publications up to date, and thus only some results obtained by our group are introduced in this part.

\subsection{Experimental apparatus}

The experimental equipments adopted in our work are shown in Figure 5, which mainly contain the reactor with stirrer, constant temperature water bath, and temperature/pressure sensor.

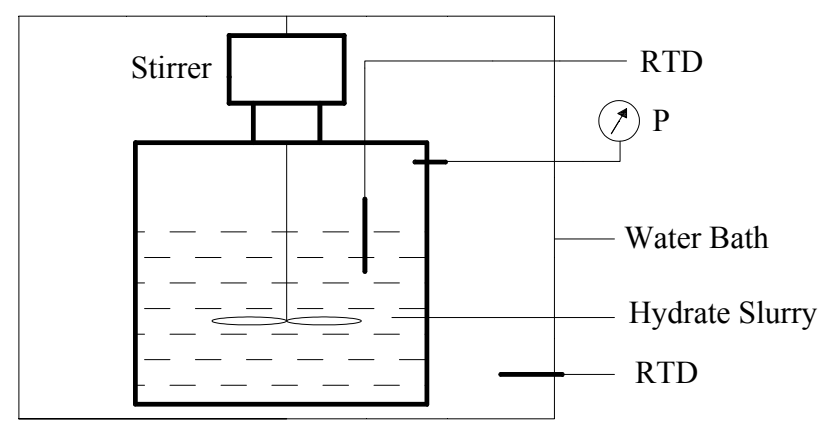

Fig. 5. The schematic outline of the experimental apparatus 


\subsection{Experimental principals and steps}

In our work the measurements were performed via the following steps:

1. The equipments were washed three to four times using distilled water;

2. The reactor was wetted using the experimental liquid, then the experimental liquid was added to the reactor until the stirrer reaches half of the height of liquid added;

3. The experimental temperature and pressure was set. We started stirring until the hydrate slurry was formed completely, then we closed the stirrer;

4. When the hydrate slurry was formed completely and the temperature was constant, the temperature of the water bath was quickly decreased by about $10 \mathrm{~K}$ to make a difference in temperature between hydrate slurry and water bath;

5. The stirrer was open at a certain stirring speed and the temperatures of both water bath and hydrate slurry were recorded at a certain interval. The stirring was stopped when the change in temperature is very small in both the water bath and the reactor.

\subsection{Experimental data analysis}

\section{(1) Calculation of the total heat transfer coefficient}

If we assume the heat released by the slurry in the reactor is equal to that adsorbed by the water bath, that is, we neglect the heat loss during the measurement, the amount of heat transfer, $\mathrm{Q}$, can be calculated with the following equation:

$$
Q=c m\left(-\frac{d T}{d t}\right)
$$

where $\mathrm{m}$ is the mass of the hydrate slurry, $\frac{d T}{d t}$ is the temperature increase/decrease per unit time, and $\mathrm{c}$ is the specific heat of the experimental liquid. The amount of heat transfer can also be calculated using the following equation:

$$
Q=K_{t} A \Delta T_{m}
$$

where $K$ is the total heat transfer coefficient, A denotes the total area of heat transfer, and $\Delta T_{m}$ is the temperature difference between the water bath and the experimental liquid. The total heat transfer coefficient can be calculated from Equations 18 and 19:

$$
K_{t}=\mathrm{cm}\left(-\frac{d T}{d t}\right) / A \Delta T_{m}
$$

\section{(2) Calculation of the heat transfer coefficient $\alpha_{1}$ of hydrate slurry}

The total heat transfer coefficient can be expressed by:

$$
\frac{1}{K_{t}}=\frac{1}{\alpha_{1}} \frac{d_{2}}{d_{1}}+\frac{b}{\lambda} \frac{d_{2}}{d_{m}}+\frac{1}{\alpha_{2}}
$$

where $d_{1}, d_{2}, d_{m}$ represent the inner, outer, and the averaged radius of the reactor, respectively, and $\lambda$ is the heat conduction coefficient of the reactor. Since in each run, $\frac{b}{\lambda} \frac{d_{2}}{d_{m}}+\frac{1}{\alpha_{2}}$ was kept constant, and thus this term can be eliminated by measuring the total 
heat transfer coefficient of pure water and hydrate slurry, and calculating the difference in the reciprocal total heat transfer coefficients of pure water and the hydrate slurry. The heat transfer coefficient of hydrate slurry can be calculated by Equation 22 then.

$$
\frac{1}{K_{\text {water }}}-\frac{1}{K_{\text {slurry }}}=\frac{1}{\alpha_{\text {water }}} \frac{d_{2}}{d_{1}}-\frac{1}{\alpha_{\text {slurry }}} \frac{d_{2}}{d_{1}}
$$

\subsection{Experimental results}

The heat transfer coefficients for both pure water and diesel oil/hydrate slurry systems with the volume fraction of hydrates of $5 \%, 10 \%, 15 \%$, and $20 \%$ were measured at $270 \mathrm{~K}$ or so. The results are shown in Figure 6.

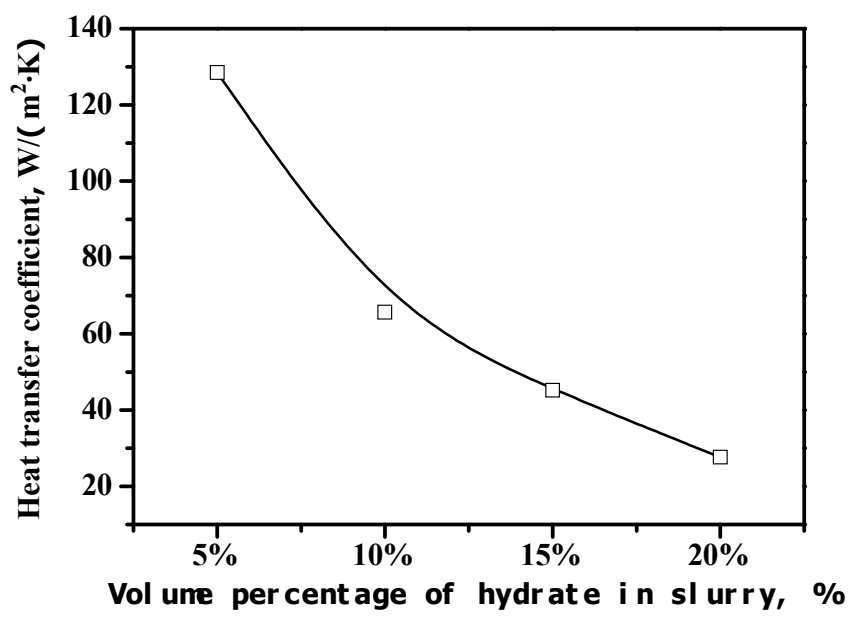

Fig. 6. Variation of heat transfer coefficient of hydrate slurry of different hydrate volume percentage

Figure 6 shows that the heat transfer coefficient decreases with increasing the content of hydrates in slurry, which can be attributed to the fact that the heat conductivity of hydrates is very small.

\section{Heat transfer in quiescent hydrate formation/dissociation reactor}

It has been well known that the hydrate formation rate can be increased drastically by adding low dose of suitable surfactants, such as sodium dodecyl sulfate (SDS). This kind of additives can enhance mass transfer involved in hydrate formation by decreasing gas/liquid interfacial tension and increasing the solubility of gas in liquid water. Then it is possible to produce gas hydrate rapidly without stirring (Lin et al., 2004; Xie et al., 2005; Zhong and Rogers, 2000). The advantage of quiescent formation of hydrate is that the cost on manufacture and maintenance of the reactor could be reduced largely. Although the mass transfer has been enhanced satisfyingly by adding SDS to water, the heat transfer becomes a serious limitation to the application of quiescent reactor as hydrate formation is an exothermic process. Rogers et al. (2005) designed a scaled-up quiescent process to store 5000 
scf of natural gas in a vessel. They thought that the primary challenge of the scale-up design was to provide a surface area/volume ratio in the larger vessel. Therefore they devised an arrangement of finned-tube heat exchanger inside the hydrate formation vessel. Their elementary tests on this process indicated that the hydrate formation in the vessel lasted more than 9 hours, which is still too long for real applications. In order to suit the large scale industrial applications, we devised a multi-deck cell-type vessel as the internals of the reactor to reduce or eliminate the scale-up effect, which is schematically shown in Figure 7 (Pang et al., 2007). The vessel basically consists of a series of uniform boxes stacked up vertically and each box is divided into a series of uniform cells by metal plates. The metal plates were welded on the heat transfer tubes; therefore they also became the cool solid surface during the hydrate formation. The SDS aqueous solution was loaded in these cells with the same level. There are interspaces between two neighboring boxes such that the hydrate forming gas can flow into each deck of the vessel easily. The multi-deck cell-type vessel was placed in the high pressure reactor so that hydrate can form in each cell of the vessel uniformly and simultaneously. In this case, the reaction time depends mainly on the cell volume and the quantity of water loaded, and little on the total volume of the vessel and total quantity of water loaded. Thus the scale-up effect can be eliminated to a large extent as concluded by Pang et al. (2007). Since then, we carried out a systematical study on heat transfer in hydrate formation/dissociation process using this vessel. Experimental details and most recent results obtained by our group which have not been published are introduced in this part.

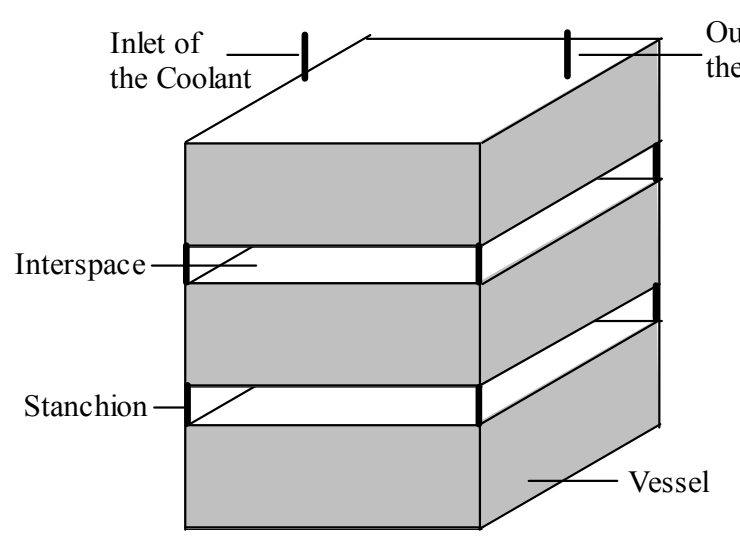

(a) Outline

(b) Cell-type inner structure

Fig. 7. The schematic outline of multi-deck cell-type vessel

\subsection{Experimental apparatus}

In order to investigate the heat transfer performance of this kind of inner structure during hydrate formation/dissociation, a middle scale reactor of a volume of 10 liter as well as an inner multi-deck cell-type vessel suitable for this reactor were manufactured and an experimental set-up, as shown in Figure 8, was established correspondingly. The reactor is $200 \mathrm{~mm}$ in diameter, $320 \mathrm{~mm}$ in height, and has a volume of $10 \mathrm{~L}$. It was sealed with a blank flange bolted to its top. 


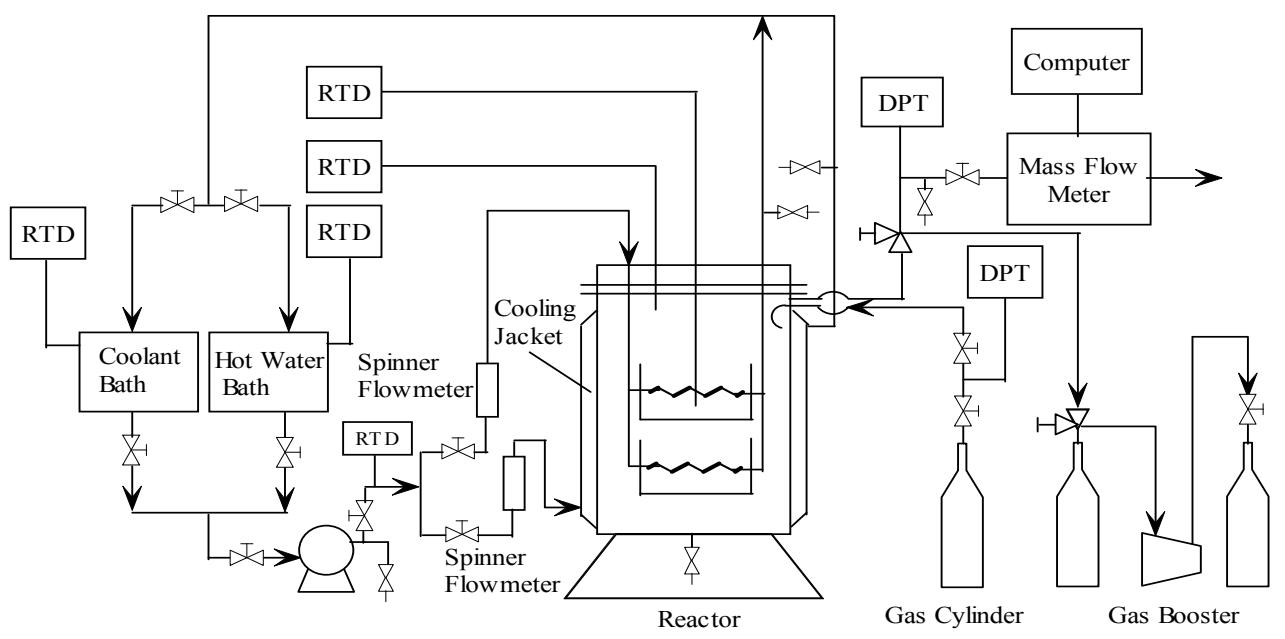

Fig. 8. Flow diagram of the experimental apparatus

Besides the stainless steel quiescent reactor, the primary components of the experimental apparatus consist of a refrigeration system and a coolant or hot water recycling system. A cooling/heating jacket was welded to the outside of the reactor and coiled copper tubes were placed inside the multi-deck cell-type vessel uniformly. Coolant or hot water was circulated through the copper tubes to cool or heat the reactant system for the hydrate formation or dissociation. The flow rate of the coolant or hot water was measured using a spinner flow meter. The coolant is a mixture of water and glycol and has a freezing point lower than $253 \mathrm{~K}$. The coolant bath was controlled by the refrigeration system within a temperature range from $253 \mathrm{~K}$ to ambient with an uncertainty of $0.1 \mathrm{~K}$. For the sake of accuracy, another platinum resistance thermometer of $\pm 0.1 \mathrm{~K}$ accuracy was placed behind the outlet of the pump to measure the temperatures of the coolant. In addition, a gas recycle system was used to recover the residual gas after the completion of hydrate formation as well as the gas released during hydrate dissociation. Two platinum resistance thermometers of $\pm 0.1 \mathrm{~K}$ accuracy were placed into the reactor from the flange to measure the temperatures of the vapor phase and the liquid (or hydrate) phase, respectively. The pressure in the reactor and the gas cylinder was measured using two calibrated Heise pressure gauges with a precision of $0.05 \mathrm{MPa}$. A mass flow meter and computer system were used to measure and record the flow rate of methane gas during the process of hydrates dissociation at atmospheric pressure. The accuracy of the flow meter is $\pm 1 \%$ F.S and the interval of record time is $5 \mathrm{~s}$.

\subsection{Experimental procedures}

\subsubsection{Hydrate formation}

Prior to any experiments the reactor was washed with water, loaded with $1920 \mathrm{~g}$ aqueous solution of $2000 \mathrm{mg} / \mathrm{L}$ SDS, and evacuated to remove air. The refrigeration system and coolant pump were then turned on to set the temperature of the aqueous solution in the reactor to $276.15 \mathrm{~K}$. After the desired temperature of the aqueous solution was achieved, methane gas was charged into the reactor until the desired pressure was achieved. During a 
hydrate formation process, the gas was charged into the reactor continuously to keep the pressure within the range of 6.4 to $6.8 \mathrm{MPa}$. When the drop in system pressure was less than $0.1 \mathrm{MPa}$ over 20 minutes, the hydrate formation process was assumed to be complete. Subsequently, the hydrate was frozen for dissociation test. In the experiment, the temperature or flux of coolant was changed to determine the effect of heat transfer on the hydrate formation rate. In each experimental run, the change of the pressure and temperature of the gas in the reactor with the elapsing time was recorded, and the mole number, $\Delta n_{i}$, of methane consumed in the time period of $\Delta t_{i}$ was then determined with the following equation:

$$
\Delta n_{i}=\frac{P_{t} V_{t}}{Z_{t} R T_{t}}-\frac{P_{t+\Delta t_{i}} V_{t+\Delta t_{i}}}{Z_{t+\Delta t_{i}} R T_{t+\Delta t_{i}}}
$$

where $V_{t}, T_{t}, P_{t}$, and $Z_{t}$ are the volume, temperature, pressure, and compressibility of the gas phase in the reactor at time $t$, respectively. $V_{t+\Delta t}, T_{t+\Delta t}, P_{t+\Delta t}$, and $Z_{t+\Delta t}$ are the volume, temperature, pressure, and compressibility of the gas phase in the reactor at the time $t+\Delta t$, respectively. It should be noted that no gas was charged into the reactor from the gas cylinder during the time period of $\Delta t_{i}$. The cumulative moles of gas consumed could be calculated readily through

$$
\Delta n=\sum_{i} \Delta n_{i}
$$

\subsubsection{Hydrate dissociation}

After hydrate samples were formed with the procedure described above and cooled down to $268.15 \mathrm{~K}$, the system was left for about 3 hours with a less than $0.1 \mathrm{~K}$ fluctuation in reactor temperature. Next, the vent was opened slowly to reduce the system pressure gradually to a bit above the equilibrium formation pressure of methane hydrate at the set temperature. Subsequently, the system was depressurized rapidly to near the atmospheric pressure of 0.1 $\mathrm{MPa}$ and the vent was then turned off. The methane hydrate samples were then heated with hot water at a fixed temperature to a complete dissociation. The history of pressure and temperature of the reactor, and the temperatures of the inlet and vent hot water were recorded with the elapsed time. During the dissociation process, the hot water was charged only into the coiled copper tubes and the coolant in the cooling jacket was expelled by air before the dissociation experiment.

The cumulative moles of methane dissociated at time $t$ without considering the shrinking of methane hydrates volume during the dissociation can be calculated with the following equation (Pang et al., 2009)

$$
\Delta n_{t}=\frac{P_{t} V_{i}}{Z_{t} R T_{t}}-\frac{P_{i} V_{i}}{Z_{i} R T_{i}}
$$

where $T_{t}, P_{t}$, and $Z_{t}$ are the temperature, pressure, and compressibility, respectively, of the gas phase in the reactor at time $t . P_{i}, V_{i}, T_{i}$, and $Z_{i}$ are the initial dissociation pressure, initial volume, initial temperature, and initial compressibility, respectively, of the gas phase in the reactor. 


\subsection{Modeling of heat transfer dependence of hydrate formation}

Englezos et al. (1987a) proposed that the hydrate formation rate was proportional to its driving force and reaction area. In our work we defined the supercooling, i.e., the difference between the equilibrium temperature and the actual reaction temperature, as the driving force, then the rate of gas consumed for hydrate growth could be formulated as

$$
\frac{d n}{d t}=K_{d} A_{g l}\left(T_{e}-T_{w}\right)
$$

where $K_{d}$ is the intrinsic hydrate formation rate constant, $A_{g l}$ is the formation area, and $T_{e}$ and $T_{w}$ are the equilibrium temperature and actual temperature of bulk water, respectively. As an exothermic reaction, the temperature of the water solution will increase with the formation of hydrate. Thus the metal plates were welded on the heat transfer tubes to remove the formation heat in the multi-deck cell-type vessel. Because of the temperature difference between the bulk water and the metal plates, the heat transfer happened and the reaction heat of hydrate formation could be expressed by

$$
\frac{d n}{d t} \Delta H=K_{h}\left(T_{w}-T_{l}\right) A_{m}+\frac{d\left(m C_{p} T\right)}{d t}
$$

where $\Delta \mathrm{H}$ is the reaction heat of hydrate formation, $K_{h}$ is the heat transfer coefficient, $T_{l}$ is the temperature of coolant, $A_{m}$ is the heat transfer area(it is assumed to be equal to the area of the metal plates), $m$ is the total quantity of water and hydrate in the vessel, $C_{p}$ is the heat capacity of mixture of water and hydrate in the vessel, and $T$ is the temperature of water and hydrate in the vessel (here we assumed that the temperature of water and hydrate is same).

As the change of temperature is not obvious during the hydrate formation, it can be assumed that most of the formation heat of hydrate formation is removed by the coolant. So Equation 27 can be simplified as

$$
\frac{d n}{d t} \Delta H=K_{h}\left(T_{w}-T_{l}\right) A_{m}
$$

Combining Equations 26 and 28 yields

$$
\frac{d n}{d t}=\left(\frac{1}{\frac{\Delta H}{K_{h} A_{m}}+\frac{1}{K_{d} A_{g l}}}\right)\left(T_{e}-T_{l}\right)
$$

Considering that the gas/water interface area decreases with the proceeding of hydrate formation, the formation area $A_{g l}$ in Equation 29 is empirically formulated as

$$
A_{g l}=A_{s}\left(1-\frac{n}{n_{s}}\right)^{b}
$$

where $A_{s}$ is the interface area of water and gas at the beginning of reaction, $n_{s}$ is the total quantity of consumed gas at the end of the reaction, $n$ is the quantity of consumed gas at 
time $t$, and $b$ is the reduced exponent of reaction area. In our work, the shape of vessel is round, and the vessel was divided into a series of uniform cells by metal plates with a 25 mm span. So the shape of most of the cells is square except the cell at the edge of the vessel, which is not regular. In our model, those irregular cells were transformed into the square cell according to the volume ratio, and the reaction status of hydrate formation in every cell was assumed to be same.

The dependence of $K_{d}$ on temperature is formulated with the following Arrhenius-type equation,

$$
K_{d}=k_{0} e^{-\frac{\Delta E}{R T}}
$$

where $k_{0}$ is the pre-exponential coefficient and $\Delta E$ is the activation energy of intrinsic hydrate formation.

\subsection{Heat transfer dependence in quiescent hydrate formation}

Heat transfer is very important for the hydrate formation. The heat of hydrate formation must be removed in time; otherwise the hydrate formation could not proceed continuously. There are two factors significantly affecting the heat transfer rate: one is the structure of the reactor, i.e., total area for heat exchange and the other one is the coolant. The effect of the structure of the reactor has been investigated by Pang et al. (2007). Our present work focuses on the effect of the coolant on the hydrate formation, including the influence of the temperature and flux of the coolant. To study the effect of the coolant on the hydrate formation and ensure all of the hydrate formation experiments are performed on the same basis, the initial temperature of reaction system, the pressure, the mass of water solution, and the concentration of surfactant SDS were uniformly specified as $276.15 \mathrm{~K}, 6.4-6.8 \mathrm{MPa}$, $1920 \mathrm{~g}$, and $2000 \mathrm{mg} / \mathrm{L}$, respectively. By changing the temperature and flux of coolant, a series of experiments have been performed, and the results are shown in Figures 9 and 10, where the hydrate formation rate was manifested by the cumulative mole numbers of consumed gas vs. elapsed time.

\subsubsection{Influence of coolant temperature}

The effect of the temperature of coolant on the hydrate formation rate is shown in Figure 9. One can see that hydrate formation rate increases with the decreasing of the coolant temperature. This is easy to understand as when the temperature of coolant is lower, the formation heat can be more easily removed. As a result, the temperature of the water solution keeps lower and the driving force of hydrate formation keeps larger, resulting in the hydrate forms faster. However, when the temperature of coolant is low enough, the consumed rate of methane gas changed little with the decreasing of the coolant temperature. It means that the effect of coolant temperature on the hydrate formation rate is limited. When the temperature of coolant is low enough, the further decreasing of temperature have little effect on the hydrate formation rate. At that time, the hydrate formation rate is not controlled by the heat transfer, but controlled by the intrinsic kinetics of hydrate formation. For comparison, the calculated results by Equation 29 are also presented in Figure 9. One can see that the agreement between experimental data and calculated results is satisfying. The parameters of model were correlated using the experimental data and are shown in Table 2, where the flux of the coolant was fixed at $5.5 \mathrm{~L} / \mathrm{min}$ and the hydrate formation heat was set to $54.20 \mathrm{KJ} / \mathrm{mol}$ (Makogon,1997). 


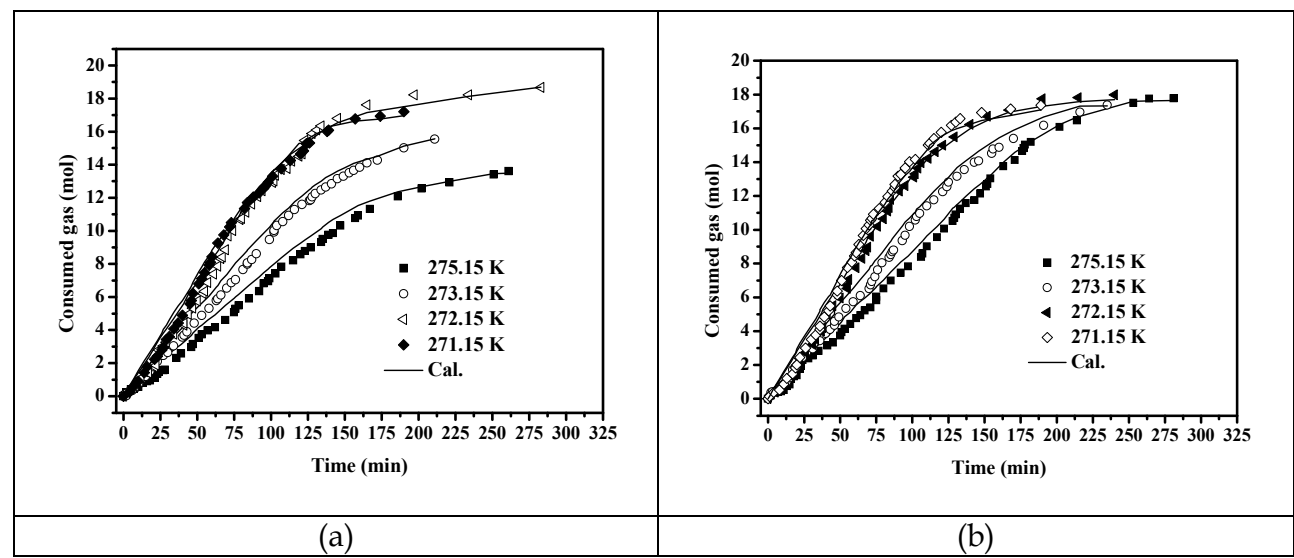

Fig. 9. The effect of the coolant temperature on hydrate formation rate at different flux of coolant: (a) $2.0 \mathrm{~L} / \mathrm{min}$ and (b) $3.5 \mathrm{~L} / \mathrm{min}$

\begin{tabular}{|c|c|c|c|c|c|c|}
\hline $\begin{array}{c}\text { Temperature } \\
\text { of coolant } \\
\mathrm{K}\end{array}$ & $\begin{array}{c}\text { System } \\
\text { temperature } \\
\mathrm{K}\end{array}$ & $\begin{array}{c}\text { Heat transfer } \\
\text { coefficient } \\
\mathrm{KW} \cdot \mathrm{m}^{-2} \cdot \mathrm{K}^{-1}\end{array}$ & $\begin{array}{c}\text { Reaction } \\
\text { rate constant } \\
\mathrm{mol} \mathrm{m}^{-2} \cdot \mathrm{K}^{-1} \cdot \mathrm{s}^{-1}\end{array}$ & $\mathrm{~b}$ & $\begin{array}{c}\Delta E \\
\mathrm{KJ} \cdot \mathrm{mol}^{-1}\end{array}$ & $\begin{array}{c}k_{0} \mathrm{~mol} \mathrm{~m}^{-2} \\
\mathrm{~K}^{-1} \cdot \mathrm{s}^{-1}\end{array}$ \\
\hline 275.15 & 281.4096 & 0.1662 & 0.0723 & 1.0030 & & \\
\hline 273.15 & 280.8802 & 0.1582 & 0.0688 & 0.8052 & & \\
\hline 272.15 & 280.1633 & 0.1808 & 0.0635 & 0.9670 & 66.467 & $1.5754 \times 10^{11}$ \\
\hline 271.15 & 279.3663 & 0.1784 & 0.0589 & 1.0938 & & \\
\hline 270.15 & 279.3233 & 0.1987 & 0.0585 & 0.9145 & & \\
\hline
\end{tabular}

Table 2. Model parameters in Equation 29 and the correlated value of $\Delta E$ and $k_{0}$

\subsubsection{Influence of coolant flux}

Experimental results showing the influence of the coolant flux on the hydrate formation rate are plotted in Figure 10. It could be seen that the hydrate formation rate increases with the increasing of coolant flux when the temperature is fixed. The effect of coolant flux on the formation rate is more significant when the temperature of coolant is higher. When the temperature of coolant is low enough, the further increase of coolant flux has little effect on increasing hydrate formation rate. In this case, hydrate formation is controlled not by the heat transfer, but by the intrinsic kinetics of hydrate formation.

\subsection{Heat transfer dependence in quiescent hydrate dissociation}

We performed a series of experiments to reveal the effect of heating on methane hydrate dissociation in the quiescent reactor (Pang et al., 2009). Representative profiles of pressure, temperature, and cumulative mole number of evolved methane during hydrate dissociation are depicted in Figure 11, where hydrate was formed from $1920 \mathrm{~g}$ water of $2000 \mathrm{mg} / \mathrm{L}$ SDS, the initial temperature of hydrate was set to $268.15 \mathrm{~K}$, the temperature of the input hot water was set to $298.15 \mathrm{~K}$, and the flow rate was set to 2.0 liter per minute (LPM). As shown in Figure 11, at the beginning of hydrate dissociation, the temperature of hydrate decreased drastically and rapidly, which indicates a brief-but-rapid dissociation induced by the rapid 
depressurization in a short time period. During this initial degassing event, the temperature of sample typically dropped 3 to $7 \mathrm{~K}$ due to adiabatic cooling of methane gas expansion as well as heat absorption of hydrate dissociation (Stern et al., 2001).

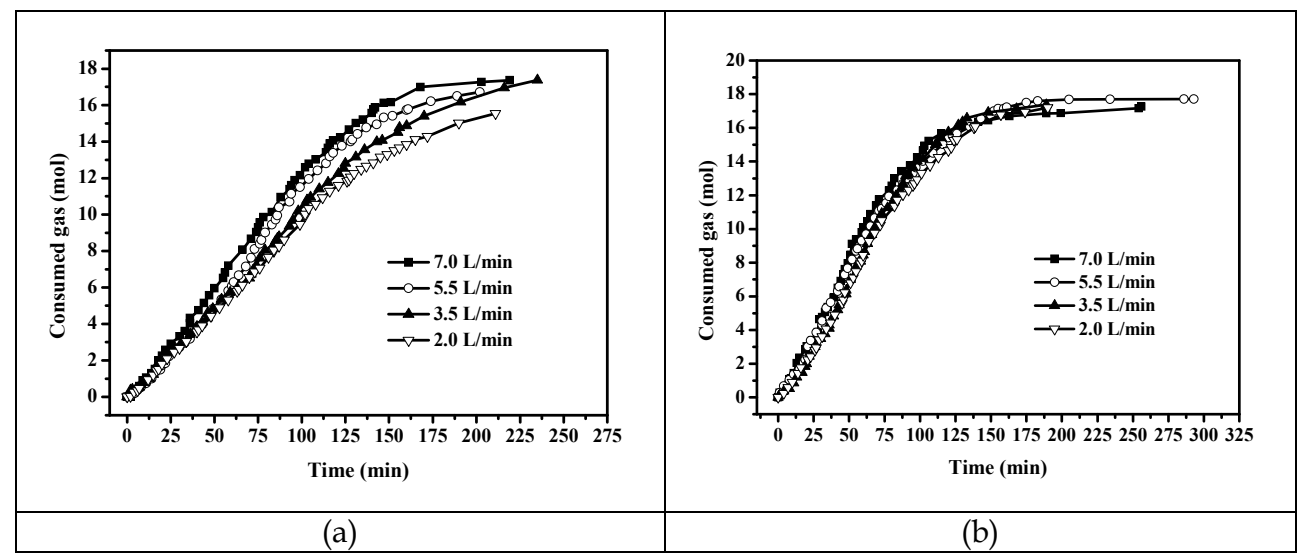

Fig. 10. The effect of the coolant flux on hydrate formation rate at different coolant temperatures: (a) $273.15 \mathrm{~K}$ and (b) $271.15 \mathrm{~K}$

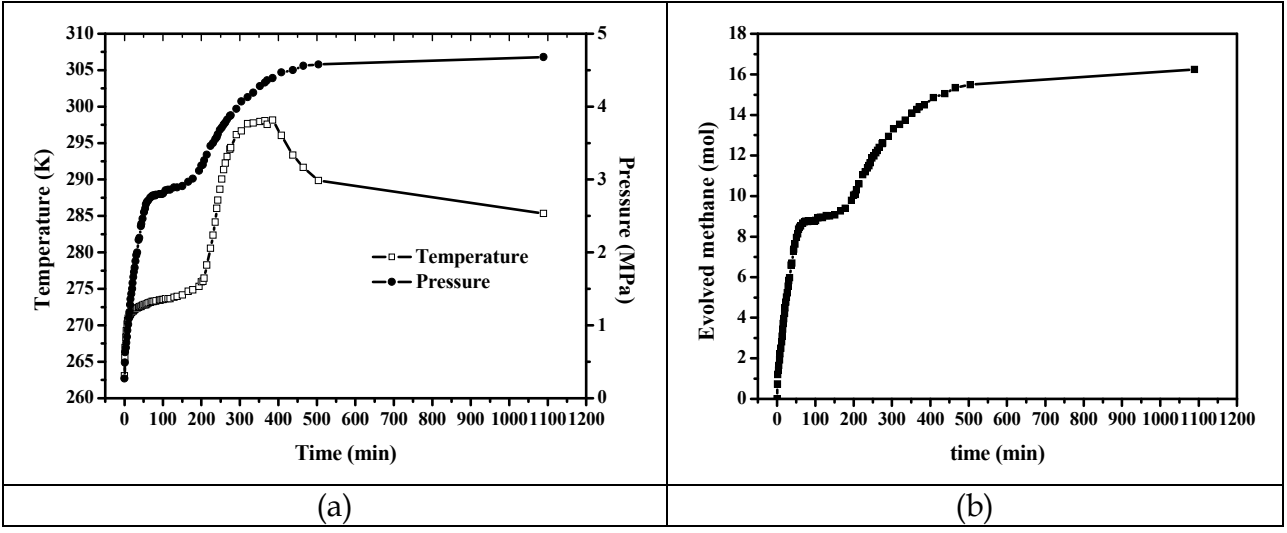

Fig. 11. Typical profiles of pressure, temperature and cumulative mole number of evolved methane during hydrate dissociation, heated by $298.15 \mathrm{~K}$ hot water of a flux of 2.0 LPM in a closed system

The temperature of hydrate and pressure of system increased sharply after the vent was turned off as the hydrates dissociated rapidly. This brief but rapid hydrate dissociation is driven mainly by the thermodynamic driving force, i.e., the difference between the equilibrium pressure and the present system pressure. Figure 12(a) shows the comparison of the experimental dissociation temperature/pressure locus with the equilibrium temperature/pressure curve of methane hydrate. It can be seen that the experimental pressure is obviously lower than the equilibrium pressure at this stage, which implies the driving force is large. 
Then a stage of buffered dissociation occurred when the hydrates was heated to approach the melting point of ice. During this period, the sample temperature remains within a narrow range near the ice point, rises slowly with the proceeding of the hydrate dissociation, and the corresponding dissociation rate is very low. As shown in Figure 12(a), the temperature/pressure locus is very close to the equilibrium temperature/pressure curve, which implies that the hydrate is closely at equilibrium state at this buffering stage and the thermodynamic driving force for hydrate dissociation is very low. At this stage, the ice coming from the hydrate dissociation is heated to produce liquid water and much larger amount of heat is required for the thaw of ice. This phase transition process buffers the system temperature at nearly fixed temperature and pressure and the rate of heat transfer is the key rate-limiting factor for the hydrate dissociation. Circone et al. $(2003,2004)$ and Stern et al. (2003) also found this kind of thermal buffering during decomposing methane hydrates by heating them from low temperature through the melting point of ice. After the buffered dissociation stage, the rate of methane hydrate dissociation increases with the increasing of temperature of heating water. Therefore, the rate of heat transfer is an important factor that controls the rate of hydrate dissociation, especially during the buffering stage. In this buffering region, the hydrate dissociation rate is very low, which is obviously unfavorable to both the recovery of gas from hydrate in the NGH technology and the gas production from in situ natural gas hydrates with heating method. Measures should be taken to eliminate this effect.

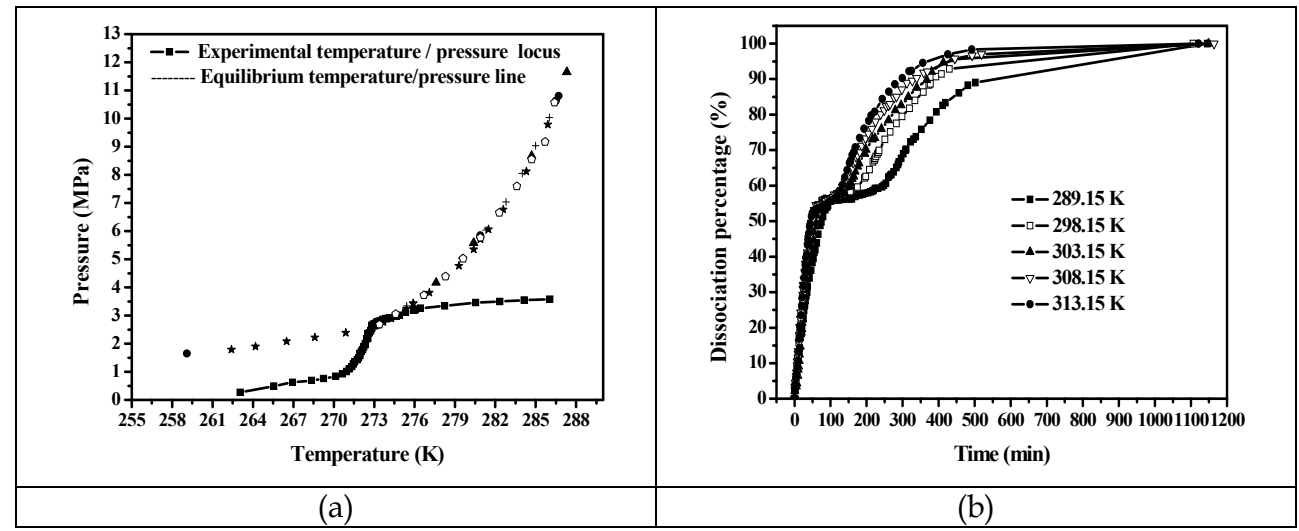

Fig. 12. (a) Comparison of the experimental dissociation temperature/pressure locus with the equilibrium temperature/pressure curve of methane hydrate, and (b) The influence of the temperature of heating water upon hydrate dissociation rate

Our previous work (Pang et al., 2009) demonstrated that the buffering effect can be eliminated and the dissociation rate can be improved by increasing the temperature of heating water or reducing the dissociation pressure. Figure 12(b) shows the influence of the temperature of heating water upon the dissociation rate of hydrate, where the dissociation rate is manifested by changing of cumulative dissociation percentage of hydrate with the elapsed time. It can be seen that the thermal buffering period can be shortened obviously by increasing heating water temperature, which suggests the important role of heat transfer in controlling the dissociation of hydrate. 


\section{Heat transfer in hydrate bearing sediment}

\subsection{Heat effect during hydrate formation in sediment}

Hydrate formation process in sediment is an exothermic process. The variation of temperature is related to the hydrate formation rate and amount. For hydrate formation in large scale of sediment, the fluctuations of temperatures at different locations will be therefore different but will coincide with specified rules. A three-dimensional apparatus has been used by our group recently to study the heat transfer process during hydrate formation in sediment (Yang et al., 2010). Sixteen thermocouples were inserted into the sediment to detect the variation of temperature, which were placed in different radius and different depth of the reactor. Figures 13 and 14 show the pressure and temperature distribution during the hydrate formation using the three-dimensional apparatus. From point A to B in Figure 13, the top pressure decreases gradually, showing the process of hydrate formation. At the same time, the temperatures at different locations in the reactor first rise to a maximum value and then decreases, as shown in Figure 14. At the initial period, the hydrate formation rate is high and temperatures rise due to the exothermic reaction. With the decline of hydrate formation rate due to the decrease of the pressure driving force and pore space, the rising trend of temperature weakens and the temperatures even decrease gradually because the exothermic effect of hydrate formation can not make up the refrigeration effect of the water bath. From point B to C, the pores of the sediment are packed with formed hydrate, which resulting in that gas at the top of the reactor can hardly permeate into the inner of sediment. Therefore, little hydrate forms and pressure and temperature nearly keep constant in this stage. From point $C$ to $D$, hydrate continues to form again, which can be implied from the magnitude of pressure decrease in Figure 13 and the temperatures increase in Figure 14. After point D, no hydrate formed and the top pressure and temperature kept constant gradually.

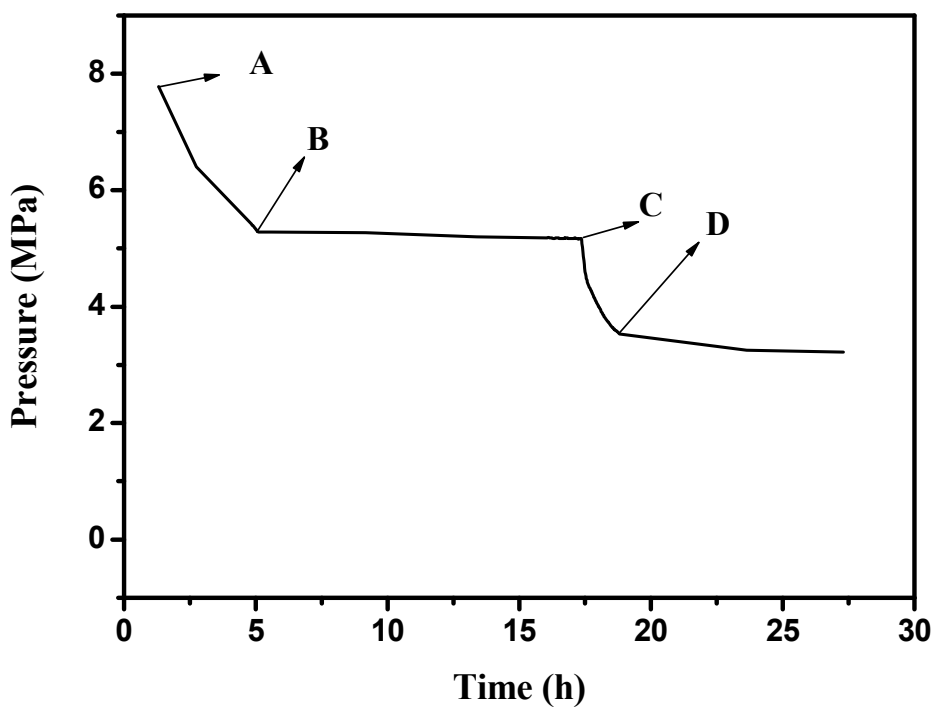

Fig. 13. Variation of pressure of the reactor versus time during hydrate formation 
During the whole process of hydrate formation, there are two stages (from A to B and C to D) of rapid increase of temperature caused by the exothermic effect of hydrate formation. The heat transfer during hydrate formation in sediment can then be characterized from the appearance sequence of the temperature peak and its magnitude.

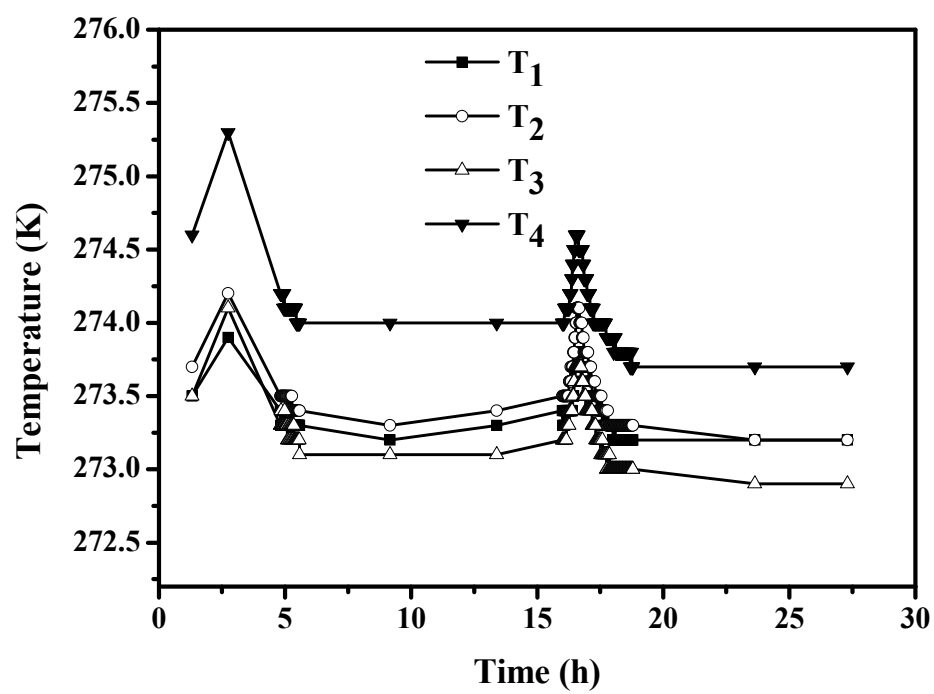

Fig. 14. Temperature distribution during hydrate formation with the same depth but different radius: $T_{1}, T_{2}, T_{3}, T_{4}$ were placed in different radius of $132 \mathrm{~mm}, 99 \mathrm{~mm}, 66 \mathrm{~mm}$, and $33 \mathrm{~mm}$, respectively

\subsection{Heat effect during hydrate dissociation in sediment}

Depressurization, to depressurize the gas hydrates reservoir below the equilibrium pressure at specified temperature, has been considered as one of conventional methods of producing gas from hydrate bearing sediment. Heat effect will arise from the Joule-Thomson effect and endothermic process of hydrate dissociation. For a typical hydrate depressurizing decomposition in a three-dimensional environment (Su et al., 2010), three steps were adopted. First, free gas is discharged until the pressure decreases to a specified value, which is close to the equilibrium pressure at the current temperature. Afterward, gas is discharged rapidly and the system pressure attains the experimental dissociation value quickly. During the rapid depressurizing stage, there exists Joule-Thomson effect, and remarkable temperature drop was observed. Hereafter, hydrate begins to decompose. The temperature begins to rise under the heat transfer of air bath and endothermic process of hydrate dissociation. The extent of temperature variation can be used to reflect the quantity of hydrate decomposed. The difference between temperature value before and after rapid depressurizing, $\Delta \mathrm{T}$, can be used to analyze the dissociation process. For the value of $\Delta \mathrm{T}$ at different positions, both Joule-Thomson effect and thermal effect of hydrate decomposition contribute to $\Delta \mathrm{T}$. Since both are endothermic process, the quantity of hydrate decomposition can be indicated by $\Delta \mathrm{T}$ value. If assuming that hydrate in the reactor decomposing at the same drive force and at the same apparent decomposition rate, the position sequence of hydrate decomposition can also be connected with $\Delta \mathrm{T}$ value. That is, the larger the $\Delta \mathrm{T}$ is, the 
earlier decomposition reaction begins. Hydrate at the top and bottom of the reactor decomposes earlier than that in the inner of the reactor.

Thermal stimulation, to produce gas from hydrates by increasing the temperature of the gas hydrates reservoir above the equilibrium temperature at specified pressure, is also an important method to produce gas from hydrate bearing sediment. Selim and Sloan (1990) found that the dissociation rate was a strong function of the thermal properties of the system and the porosity of the porous medium. Kamata et al. (2005) applied thermal recovery method to dissociate methane hydrate in hydrate sediment sample by hot-water injection from one side, gas production from another side. It was found that temperature and pressure in the sample fluctuated between stability region and decomposition region of methane hydrate sample when temperature of the hot water was high. We (Yang et al., 2010) studied the temperature distributions in the reactor during gas production by cyclic injecting hot water method. Figure 15 shows the variation of temperatures with time at different locations during the first cycle and the second cycle. It can be found that the overall temperature trend increases with hot-water injection and decreases with gas production. At initial stage of water injection, the temperatures rise slowly due to much heat is consumed to warm the flowing channel of hot-water. Afterward, the temperatures at different locations rise rapidly. It is noted that for the local positions of hydrate sample which are away from the injecting well and near the reactor wall, the temperature-jump phenomenon is not observed. It is known that the hot-water can hardly spread to those locations in a shorter time. Strong heat exchange with environment may also occur on those positions near the reactor wall with high conductivity. In contrast, at other locations, in view of low conductivity of hydrate sample, the fluctuation of temperature mainly depends on the seepage rate of hot-water in sediments instead of thermal diffusion. That is to say, the seepage flow controls the heat transport in this process at these locations. In addition, the temperature distribution also implied the injected hot-water distribution in the reactor to a certain extent. The location of well has an important effect on the temperature distribution in hydrate sediment, thereby affecting the gas production.

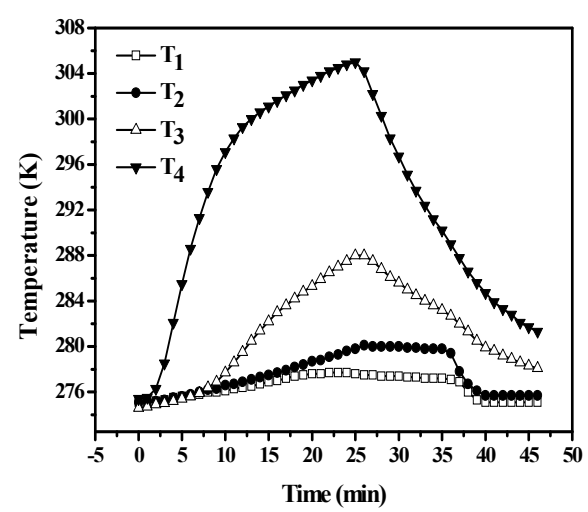

(a) first cycle

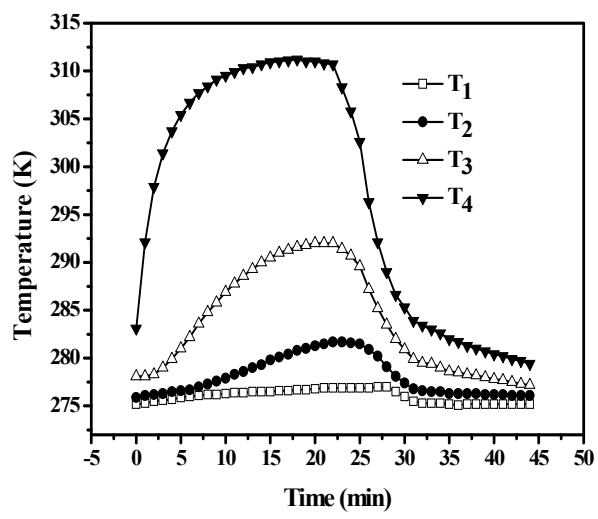

(b) second cycle

Fig. 15.Variation of temperature with time at different locations with the same depth during the first cycle: $T_{1}, T_{2}, T_{3}, T_{4}$ were placed in different radius of $132 \mathrm{~mm}, 99 \mathrm{~mm}, 66 \mathrm{~mm}$, and 33 $\mathrm{mm}$, respectively 


\section{Conclusion}

In this chapter we have discussed heat transfer involved in formation/dissociation of gas hydrates. The state of the art for the studies of the experimental measurement of thermal conductivities of different kinds of gas hydrates, the mechanism and modeling of heat transfer occurring in the growth of hydrate film at the guest/water interface, our experimental study on macroscopic heat transfer in stirring reactors or flowing pipes, the experimental and modeling studies on the heat transfer in quiescent reactors, and the mechanism of heat transfer in hydrate bearing-sediment are summarized. We believe this chapter will be helpful for readers to understand the critical position of heat transfer in the hydrate formation/dissociation kinetics, favor the ongoing hydrate formation/dissociation kinetic research, and promote the application of gas hydrate.

\section{Acknowledgement}

The financial supports of the NSFC (Nos. 20925623, 21006126), the Research Funds of China University of Petroleum, Beijing (BJBJRC-2010-01), and the National Basic Research Program of China (2009CB219504) are greatly appreciated.

\section{References}

Andersson P. \& Ross R. G. (1983). Effect of guest molecule size on the thermal conductivity and heat capacity of clathrate hydrates. J. Phys. C, Vol. 16, pp. 1423-1432.

Circone S., Stern L. A., Kirby S. H., Durham W. B., Chakoumakos B. C., Rawn C. J., Rondinone A. J. \& Ishii Y. (2003). $\mathrm{CO}_{2}$ hydrate: synthesis, composition, structure, dissociation behavior, and a comparison to structure $\mathrm{I} \mathrm{CH}_{4}$ hydrate. J. Phys. Chem. B, Vol. 107, pp. 5529-5539.

Circone S., Stern L. A. \& Kirby S. H. (2004). The role of water in gas hydrate dissociation. J. Phys. Chem. B, Vol. 108, pp. 5747-5755.

Cook J. G. \& Laubitz M. J. (1983). In Thermal Conductiuity; Hust J. G., Ed.; Plenum: New York, Vol. 17, pp. 745.

Cortes D. D., Martin A. I., Yun T. S., Francisca F. M., Santamarina J. C. \& Ruppel C. (2009). Thermal conductivity of hydrate-bearing sediments. J. Geophys. Res., Vol. 114, pp. B11103.

deMartin B. J. (2001). Laboratory measurements of the thermal conductivity and thermal diffusivity of methane hydrate at simulated in-situ conditions. Georgia Institute of Technology: Atlanta, GA, USA.

Englezos P., Kalogerakis N. E., Dholabhai P. D. \& Bishnoi P. R. (1987a). Kinetics of formation of methane and ethane gas hydrates. Chem. Eng. Sci., Vol. 42, pp. 2647-2658.

Englezos P., Kalogerakis N. E., Dholabhai P. D. \& Bishnoi P. R. (1987b). Kinetics of gas hydrate formation from mixtures of methane and ethane. Chem. Eng. Sci., Vol. 42, pp. 2659-2666.

English, N. J. \& Tse, J. S. (2010). Perspectives on hydrate thermal conductivity. Energies, Vol. 3, pp. 1934-1942.

Freer, E. M., Selim, M. S. \& Sloan, E. D. (2001). Methane hydrate film growth kinetics. Fluid Phase Equilib., Vol. 185, pp. 65-75. 
Gustafsson S. E., Karawacki E. \& Khan M. N. (1979). Transient hot-strip method for simultaneously measuring thermal conductivity and thermal diffusivity of solid sand fluids. J. Phys. D: Appl. Phys., Vol. 12, pp.1411.

Gustafsson S. E., Karawacki E. \& Chohan M. A. (1986). Thermal transport studies of electrically conducting materials using the transient hot-strip technique. J. Phys. D: Appl. Phys., Vol. 19, pp. 727.

Handa Y. P. \& Cook J. G. (1987). Thermal conductivity of xenon hydrate. J. Phys. Chem., Vol. 91, pp. 6327-6328.

Huang D. Z. \& Fan S. S. (2004). Thermal conductivity of methane hydrate formed from sodium dodecyl sulfate solution. J. Chem. Eng. Data, Vol. 49, pp. 1479-1482.

Huang D. Z., Fan S. S. \& Shi L. (2004). Thermal conductivity of gas hydrate. Huaxuetongbao, Vol. 10, pp. 737-742. (in Chinese)

Kamata Y., Ebinuma T., Omura R., Minagawa H., Narita H., Masuda Y. \& Konno Y. (2005). Decomposition experiment of methane hydrate sediment by thermal recovery method. Proceedings of the 5th International Conference on Gas Hydrates, Trondheim, Norway, pp. 81-85.

Krivchikov A. I., Gorodilov B. Y., Korolyuk O. A., Manzhelii V. G., Conrad H. \& Press W. (2005). Thermal conductivity of methane-hydrate. J. Low Temp. Phys., Vol. 139, pp. 693-702.

Krivchikov A. I., Gorodilov B. Y., Korolyuk O. A., Manzhelii V. G., Romantsova O. O., Conrad H., Press W., Tse J. S. \& Klug D. D. (2006). Thermal conductivity of Xe clathrate hydrate at low temperatures. Phys. Rev. B, Vol. 73, pp. 064203.

Li D. L., Liang D. Q., Fan S. S. \& Peng H. (2010). Estimation of ultra-stability of methane hydrate at $1 \mathrm{~atm}$ by thermal conductivity measurement. J. Nat. Gas. Chem., Vol. 19, pp. 229-233.

Lin W., Chen G. J., Sun C. Y., Guo X. Q., Wu Z. K., Liang M. Y., Chen L. T. \& Yang L. Y. (2004). Effect of surfactant on the formation and dissociation kinetic behavior of methane hydrate. Chem. Eng. Sci., Vol. 59, pp. 4449-4455.

Lunden A., Trolle U., Azoulay M. \& de Pablo J. (1986). Determination of kinetics and thermal conductivity of hydrates simultaneously by using thermogravimetry and transient hot strip method. Thermochimica Acta, Vol. 105, pp. 369-373.

Ma C. F., Chen G. J. \& Guo T. M. (2002). Kinetics of hydrate formation using gas bubble suspended in water. Science in China (Series B), Vol. 45, pp. 208-215.

Makogon Y. F. (1997). Hydrates of Hydrocarbons. Tulsa, Oaklahoma: Penn Well books.

Mochizuki T. \& Mori Y. H. (2006). Clathrate-hydrate film growth along water/hydrateformer phase boundaries-numerical heat-transfer study. J. Crystal. Growth, Vol. 290, pp. 642-652.

Moon C., Taylor P. C. \& Rodger P. M. (2003). Molecular dynamic study of gas hydrate formation. J. Am. Chem. Soc., Vol. 125, pp. 4706-4707.

Mori Y. H. (2001). Estimating the thickness of hydrate films from their lateral growth rates: application of a simplified heat transfer model. J. Crystal. Growth, Vol. 223, pp. 206212.

Ohmura R., Kashiwazaki S. \& Mori Y. H. (2000). Measurements of clathrate-hydrate film thickness using laser interferometry. J. Crystal. Growth, Vol. 218, pp. 372-380.

Ohmura R., Matsuda S., Uchida T., Ebinuma T. \& Narita H. (2005). Clathrate hydrate crystal growth in liquid water saturated with a guest substance: observations in a methane + water system. Cryst. Growth Des., Vol. 5, pp. 953-957. 
Pang W. X., Chen G. J., Dandekar A., Sun C. Y. \& Zhang C. L. (2007). Experimental study on the scale-up effect of gas storage in the form of hydrate in a quiescent reactor. Chem. Eng. Sci., Vol. 62, pp. 2198-2208.

Pang W. X., Xu W. Y., Sun C. Y., Zhang C. L. \& Chen G. J. (2009). Methane hydrate dissociation experiment in middle-sized quiescent reactor using thermal method. Fuel, Vol. 88, pp. 497-503.

Peng B. Z., Chen G. J., Sun C. Y., Yang L. Y. \& Luo H. (2008). Is the gas hydrate film growth controlled by intrinsic kinetic or heat transfer? Proceedings of the 6th international conference on gas hydrates, Vancouver, British Columbia, Canada.

Peng B. Z., Dandekar A., Sun C. Y., Luo H., Ma Q. L., Pang W. X. \& Chen G. J. (2007). Hydrate film growth on the surface of a gas bubble suspended in water. J. Phys. Chem. B, Vol. 111, pp. 12485-12493.

Peng B. Z., Sun C. Y., Chen G. J., Yang L. Y., Zhou W. \& Pang W. X. (2009). Hydrate film growth at the interface between gaseous $\mathrm{CO}_{2}$ and sodium chloride solution. Science in China Series B: Chemistry, Vol. 52, pp. 676-682.

Rogers R. E., Zhong Y., Etheridge J. A., Arunkumar R., Pearson L. E. \& Hogancamp T. K. (2005). Micellar gas hydrates storage process. Proceedings of the 5th international conference on gas hydrates, Trondheim, Norway, pp. 1361-1365.

Rosenbaum E. J., English N. J., Johnson J. K., Shaw D. W. \& Warzinski R. P. (2007). Thermal conductivity of methane hydrate from experiment and molecular simulation. $J$. Phys. Chem. B, Vol. 111, pp. 13194-13205.

Ross R. G. \& Andersson P. (1982). Clathrate and other solid phases in the tetrahydrofuranwater system: thermal conductivity and heat capacity under pressure. Can. J. Chem., Vol. 60, pp. 881-892.

Ross R. G., Andersson P. \& Backstrom G. (1981). Unusual PT dependence of thermalconductivity for a clathrate hydrate. Nature, Vol. 290, pp. 322.

Saito K., Kishimoto M., Tanaka R. \& Ohmura R. (2011). Crystal growth of clathrate hydrate at the interface between hydrocarbon gas mixture and liquid water. Crystal. Growth $\mathcal{E}$ Design, Vol.11, pp. 295-301.

Saito K., Sum A. K. \& Ohmura R. (2010). Correlation of hydrate-film growth rate at the guest/liquid-water interface to mass transfer resistance. Ind. Eng. Chem. Res., Vol. 49, pp. 7102-7103.

Selim M. S. \& Sloan E. D. (1990). Hydrate dissociation in sediments. SPE Reserv. Eng., Vol. 5, pp. 245-251.

Sloan E. D. \& Koh C. A. (2007). Clathrate hydrate of natural gases. $3^{\text {rd }}$ ed, CRC Press: Boca Raton, FL.

Stern L. A., Circone S., Kirby S. H. \& Durham W. B. (2001). Anomalous preservation of pure methane hydrate at $1 \mathrm{~atm}$. J. Phys. Chem. B, Vol. 105, pp. 1756-1762.

Stern L. A., Circone S., Kirby S. H. \& Durham W. B. (2003). Temperature, pressure, and compositional effects on anomalous or "self" preservation of gas hydrates. Can. J. Phys., Vol. 81, pp. 271-283.

Stoll R. D. \& Bryan, G. M. (1979). Physical properties of sediments containing gas hydrates. J. Geophys. Res., Vol. 84, pp. 1629-1634.

Su K. H., Sun C. Y., Yang X., Chen G. J. \& Fan S. S. (2010). Experimental investigation of methane hydrate decomposition by depressurizing in porous media with 3Dimension device. J. Nat. Gas Chem., Vol. 19, pp. 210-216. 
Sun C. Y., Chen G. J., Ma C. F., Huang Q., Luo H. \& Li Q. P. (2007). The growth kinetics of hydrate film on the surface of gas bubble suspended in water or aquesou surfactant solution. J. Crystal. Growth, Vol. 306, pp. 491-499.

Taylor C. J., Miller K. Y., Koh C. A. \& Sloan E. D. (2007). Macroscopic investigation of hydrate film growth at the hydrocarbon/water interface. Chem. Eng. Sci., Vol. 62, pp. 6524-6533.

Tse J. S. \& White M. A. (1988). Origin of glassy crystalline behavior in the thermal properties of clathrate hydrates: A thermal conductivity study of tetrahydrofuran hydrate. J. Phys. Chem., Vol. 92, pp. 5006-5011.

Tzirita A. (1992). In situ detection of natural gas hydrates using electrical and thermal properties. Ph.D. thesis, Texas A\&M Univ., College Station.

Uchida T., Ebinuma T., Kawabata J. \& Narita H. (1999). Microscopic observations of formation processes of clathrate-hydrate films at an interface between water and carbon dioxide. J. Crystal. Growth, Vol. 204, pp. 348-356.

Uchida T., Ikeda I. Y., Yakeya S., Ebinuma T., Nagao J. \& Narita H. (2002). CO 2 hydrate film formation at the boundary between $\mathrm{CO}_{2}$ and water: effects of temperature, pressure and additives on the formation rate. J. Crystal. Growth, Vol. 237, pp. 383-387.

Vysniauskas Y. \& Bishnoi P. R. (1983). A kinetic study of methane hydrate formation. Chem. Eng. Sci., Vol. 38, pp. 1061-1072.

Waite W. F., Gilbert L. Y., Winters W. J. \& Mason D. H. (2005). Thermal property measurements in Tetrahydrofuran (THF) hydrate and hydrate bearing sediment between -25 and $+40 \mathrm{C}$, and their application to methane hydrate. Paper presented at 5th International Conference on Gas Hydrates, Tapir Acad., Trondheim, Norway.

Waite W. F., Stern L. A., Kirby S. H., Winters W. J. \& Mason D. H. (2007). Simultaneous determination of thermal conductivity, thermal diffusivity and specific heat in sI methane hydrate. Geophys. J. Int., Vol. 169, pp. 767-774.

Xie Y. M., Guo K. H., Liang D. Q., Fan S. S. \& Gu J.M. (2005). Steady gas hydrate growth along vertical heat transfer tube without stirring. Chem. Eng. Sci., Vol. 60, pp. 777786.

Yamamoto Y., Ohtake M., Kawamura T., Tsuji T. \& Tsukada Y. (2008). Thermal conductivity measurement of methane hydrate with soil. Proceedings of the 6th international conference on gas hydrates, Vancouver, British Columbia, Canada.

Yang X., Sun C. Y., Yuan Q., Ma P. C. \& Chen G. J. (2010). Experimental study on gas production from methane hydrate-bearing sand by hot-water cyclic injection. Energy \& Fuels, Vol. 24, pp. 5912-5920.

Zhong Y. \& Rogers R. E. (2000). Surfactant effects on gas hydrate formation. Chem. Eng. Sci., Vol. 55, pp. 4175-4187. 


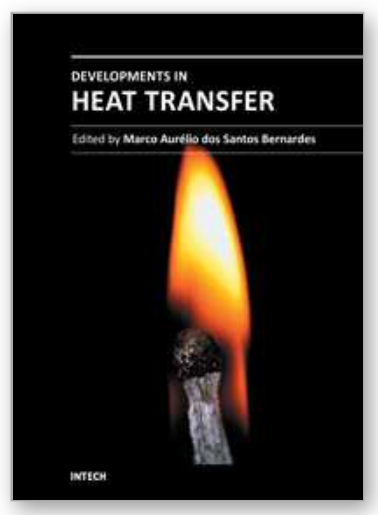

\author{
Developments in Heat Transfer \\ Edited by Dr. Marco Aurelio Dos Santos Bernardes
}

ISBN 978-953-307-569-3

Hard cover, 688 pages

Publisher InTech

Published online 15, September, 2011

Published in print edition September, 2011

This book comprises heat transfer fundamental concepts and modes (specifically conduction, convection and radiation), bioheat, entransy theory development, micro heat transfer, high temperature applications, turbulent shear flows, mass transfer, heat pipes, design optimization, medical therapies, fiber-optics, heat transfer in surfactant solutions, landmine detection, heat exchangers, radiant floor, packed bed thermal storage systems, inverse space marching method, heat transfer in short slot ducts, freezing an drying mechanisms, variable property effects in heat transfer, heat transfer in electronics and process industries, fission-track thermochronology, combustion, heat transfer in liquid metal flows, human comfort in underground mining, heat transfer on electrical discharge machining and mixing convection. The experimental and theoretical investigations, assessment and enhancement techniques illustrated here aspire to be useful for many researchers, scientists, engineers and graduate students.

\title{
How to reference
}

In order to correctly reference this scholarly work, feel free to copy and paste the following:

Bei Liu, Weixin Pang, Baozi Peng, Changyu Sun and Guangjin Chen (2011). Heat Transfer Related to Gas Hydrate Formation/Dissociation, Developments in Heat Transfer, Dr. Marco Aurelio Dos Santos Bernardes (Ed.), ISBN: 978-953-307-569-3, InTech, Available from: http://www.intechopen.com/books/developments-inheat-transfer/heat-transfer-related-to-gas-hydrate-formation-dissociation

\section{INTECH}

open science | open minds

\section{InTech Europe}

University Campus STeP Ri

Slavka Krautzeka 83/A

51000 Rijeka, Croatia

Phone: +385 (51) 770447

Fax: +385 (51) 686166

www.intechopen.com

\section{InTech China}

Unit 405, Office Block, Hotel Equatorial Shanghai

No.65, Yan An Road (West), Shanghai, 200040, China

中国上海市延安西路65号上海国际贵都大饭店办公楼 405 单元

Phone: +86-21-62489820

Fax: $+86-21-62489821$ 
(C) 2011 The Author(s). Licensee IntechOpen. This chapter is distributed under the terms of the Creative Commons Attribution-NonCommercialShareAlike-3.0 License, which permits use, distribution and reproduction for non-commercial purposes, provided the original is properly cited and derivative works building on this content are distributed under the same license. 